(2)

\title{
Angiotensin II induces differential insulin action in rat skeletal muscle
}

\section{Juthamard Surapongchai', Mujalin Prasannarong ${ }^{2}$, Tepmanas Bupha-Intr' ${ }^{1}$ and Vitoon Saengsirisuwan'}

${ }^{1}$ Exercise Physiology Laboratory, Department of Physiology, Faculty of Science, Mahidol University, Bangkok, Thailand

2Department of Physical Therapy, Faculty of Associated Medical Sciences, Chiang Mai University, Chiang Mai, Thailand
Correspondence

should be addressed

to V Saengsirisuwan

Email

vitoon.sae@mahidol.ac.th

\begin{abstract}
Angiotensin II (ANGII) is reportedly involved in the development of skeletal muscle insulin resistance. The present investigation evaluated the effects of two ANGII doses on the phenotypic characteristics of insulin resistance syndrome and insulin action and signaling in rat skeletal muscle. Male Sprague-Dawley rats were infused with either saline (SHAM) or ANGII at a commonly used pressor dose (100 ng/kg/min; ANGII-100) or a higher pressor dose ( $500 \mathrm{ng} / \mathrm{kg} / \mathrm{min}$; ANGII-500) via osmotic minipumps for 14 days. We demonstrated that ANGII-100-infused rats exhibited the phenotypic features of nonobese insulin resistance syndrome, including hypertension, impaired glucose tolerance and insulin resistance of glucose uptake in the soleus muscle, whereas ANGII-500-treated rats exhibited diabetes-like symptoms, such as post-prandial hyperglycemia, impaired insulin secretion and hypertriglyceridemia. At the cellular level, insulin-stimulated glucose uptake in the soleus muscle of the ANGII-100 group was 33\% lower $(P<0.05)$ than that in the SHAM group and was associated with increased insulin-stimulated IRS-1 Ser ${ }^{307}$ and decreased Akt Ser ${ }^{473}$ and AS160 Thr ${ }^{642}$ phosphorylation and GLUT-4 expression. However, ANGII-500 infusion did not induce skeletal muscle insulin resistance or impair insulin signaling elements as initially anticipated. Moreover, we found that insulinstimulated glucose uptake in the ANGII-500 group was accompanied by the enhanced expression of ACE2 and MasR proteins, which are the key elements in the non-classical pathway of the renin-angiotensin system. Collectively, this study demonstrates for the first time that chronic infusion with these two pressor doses of ANGII induced differential metabolic responses at both the systemic and skeletal muscle levels.
\end{abstract}

Journal of Endocrinology (2017) 232, 547-560

\section{Introduction}

Insulin resistance of skeletal muscle represents a major defect in the maintenance of euglycemia and is often accompanied by a variety of metabolic and cardiovascular abnormalities, including glucose intolerance, hyperinsulinemia, hypertension, dyslipidemia, obesity and atherosclerosis. A cluster comprising these diabetic and atherogenic risk factors is known as insulin resistance syndrome (Reaven 2005, DeFronzo \& Tripathy 2009). Increasing evidence indicates a link among insulin resistance, hypertension and the development of diabetes. For example, hypertensive individuals have higher fasting glucose and insulin levels than non-hypertensive

Published by Bioscientifica Ltd. 
individuals, whereas patients with untreated hypertension are more likely to develop new-onset diabetes than nonhypertensive subjects (Gress et al. 2000, Bosch et al. 2006).

Angiotensin II (ANGII), a vasoactive peptide of the renin-angiotensin system (RAS), has been defined as one of the major causes of hypertension and is involved in the development of insulin resistance condition (Sower 2004, de Kloet et al. 2010, Luther \& Brown 2011). In support of this, a higher level of plasma ANGII has been demonstrated to be associated with diabetic severity (Nicola et al. 2001). Clinical observation has demonstrated that patients with essential hypertension have plasma ANGII levels that are 2- to 4-fold higher than levels in healthy individuals, whereas renal hypertensive patients can demonstrate an 8 -fold increase in plasma ANGII levels (Catt et al. 1969). ANGII infusion via implantable osmotic minipumps has been widely used as an experimental model to investigate the pathological processes in organs as well as disease conditions (Qin 2008). It has been reported that a more commonly used dose, $100 \mathrm{ng} / \mathrm{kg} / \mathrm{min}$, increased plasma ANGII levels by 2 -fold, whereas a high pressor dose of ANGII infused at $500 \mathrm{ng} / \mathrm{kg} / \mathrm{min}$ increased plasma ANGII levels by 4 - to 6 -fold and aggravated hypertensive conditions (Staroukine et al. 1984). Of note, studies examining the impact of ANGII infusion on insulin action have yielded inconsistent results (Ogihara et al. 2002, Lastra et al. 2013). Therefore, we hypothesized that the extent to which ANGII modulates insulin action on glucose transport activity and related signaling elements in skeletal muscle can be affected by the dose of ANGII.

Recently, the ACE2/ANG(1-7)/MasR axis is viewed as an alternative RAS system that counters the deleterious actions of the ACE/ANGII/AT1R axis. For example, activation of the ACE2/ANG(1-7)/MasR axis improved glucose and lipid metabolism (Ferrario et al. 2005, Santos et al. 2008, 2013, Prasannarong et al. 2012a, Echeverria-Rodriguez et al. 2014, Santos \& Andrade 2014). However, it remains unknown whether insulin resistance of skeletal muscle glucose transport activity induced by ANGII infusion is associated with changes in the expression of proteins in the ACE2/ANG(1-7)/MasR axis.

In light of this information, the present study was designed to test the following hypotheses: (1) ANGII induces cardiometabolic abnormalities and impairs insulin-stimulated glucose uptake in skeletal muscle in a dose-dependent fashion and (2) ANGII-induced skeletal muscle insulin resistance would be accompanied with disruptions of the insulin signaling pathway and the ACE2/ANG(1-7)/MasR axis. To address these issues, we investigated the extent to which ANGII infusion at a more commonly used dose (100ng/kg/min; ANGII-100) and a high pressor dose $(500 \mathrm{ng} / \mathrm{kg} / \mathrm{min}$; ANGII-500) modulate arterial pressure, glucose tolerance, serum triglyceride levels, insulin-stimulated skeletal muscle glucose transport activity, the protein expression and phosphorylation status of the signaling molecules known to be involved in the glucose transport process and the expression of key proteins in the RAS pathways in male Sprague-Dawley rats.

\section{Materials and methods}

\section{Animal treatment}

Eight-week-old male Sprague-Dawley rats, weighing between 260 and $290 \mathrm{~g}$, supplied by the National Laboratory Animal Center, Thailand, were housed at the Center of Animal Facilities, Faculty of Science, Mahidol University. The housing unit was controlled at $22^{\circ} \mathrm{C}$ with a 12/12-h light/dark cycle (light on from 06:00 to 18:00 h), and the animals had free access to water and pellet rat chow (Perfect Companion, Samutprakarn, Thailand). The rats were randomly assigned to either a sham operation (SHAM, $n=10$ ) or chronic ANGII infusion $(n=20)$. Subcutaneous implantation of Alzet osmotic minipumps (model 2002) (Durect Cooperation, Cupertino, CA, USA) in rats occurred on the back, slightly posterior to the scapulae. The surgery was performed under anesthesia following the company's recommended procedure. The SHAM group was infused with normal saline. ANGII was dissolved in saline acidified with $0.01 \mathrm{M}$ acetic acid to maintain its stability and was infused at a rate of 100 or $500 \mathrm{ng} / \mathrm{kg} / \mathrm{min}$. Body weight, food and water intake were monitored regularly during the 14-day experimental period. All animal procedures were approved by the Animal Care and Use Committee, Faculty of Science, Mahidol University, in accordance with the International Guiding Principles for Biomedical Research Involving Animals of the Council for International Organizations of Medical Sciences.

\section{Blood pressure determination}

One week before the treatment began, animals were acclimated to the tail-cuff plethysmography apparatus (CODA Monitor System, Kent Scientific Corporation, Torrington, CT, USA) by placing the animal in a holding tube with the pressure cuff at the base of the animal's tail. The systolic blood pressure (SBP), diastolic blood pressure (DBP), mean arterial pressure (MAP) and heart rate (HR)

Published by Bioscientifica Ltd 
were measured in conscious rats before implantation of osmotic minipumps and 5 and 10 days after the implantation. The mean of ten consecutive readings was used for the reported value of SBP, DBP, MAP and HR for each rat.

\section{Oral glucose tolerance test (OGTT)}

Following 10 days of the ANGII infusion, an oral glucose tolerance test was performed to determine insulin sensitivity at the whole body level. In the evening (18:00 h) of the day before the test, each rat was food-restricted to $4 \mathrm{~g}$ of chow. The next morning (08:00-09:00 h), $0.5 \mathrm{~mL}$ of tail blood was collected before and 15, 30, 60 and $120 \mathrm{~min}$ after glucose feeding $(1 \mathrm{~g} / \mathrm{kg} \mathrm{BW})$ by gavage. Blood samples were mixed with EDTA as an anticoagulant, and plasma samples were prepared. Each animal was given $2.5 \mathrm{~mL}$ of sterile $0.9 \%$ saline subcutaneously immediately after the test to replace fluid loss. Plasma was used to determine the levels of glucose by colorimetric assay (Gesellschaft fur Biochemica and Dianostica, Wiesbadan, Germany) and insulin by radioimmunoassay (Linco Research).

\section{Insulin action on skeletal muscle glucose transport activity}

The ANGII infusion continued for four days after the OGTT. All animals were food-restricted as described above. At 08:00h, animals were weighed and anesthetized with an intraperitoneal injection of thiopental $(100 \mathrm{mg} / \mathrm{kg}$ body wt). Soleus muscles were isolated and prepared for in vitro incubation. The two soleus muscles were divided into three strips each. Two non-incubated soleus strips were quickly frozen in liquid nitrogen for subsequent analyses of signaling proteins. Four fresh soleus strips $(\sim 25 \mathrm{mg})$ were incubated for $30 \mathrm{~min}$ at $37^{\circ} \mathrm{C}$ in $3 \mathrm{~mL}$ of oxygenated Krebs-Henseleit buffer (KHB) supplemented with $8 \mathrm{mM}$ D-glucose, $32 \mathrm{mM}$ D-mannitol and $0.1 \%$ radioimmunoassay-grade bovine serum albumin (Sigma Chemical, St Louis, MO, USA). Two of these four muscle strips were incubated in the absence of insulin, and the other two were incubated in the presence of a maximally effective concentration of insulin $(2 \mathrm{mU} / \mathrm{mL}$; Human R, Eli Lilly). The flasks were continuously gassed with a mixture of $95 \% \mathrm{O}_{2}$ and $5 \% \mathrm{CO}_{2}$ throughout the incubation and glucose transport assay. After the first incubation period, two of the soleus strips (one incubated without insulin and one incubated with insulin) were removed, trimmed of fat and connective tissue and quickly frozen in liquid nitrogen. These strips were subsequently used for the determination of signaling elements in response to insulin activation by immunoblotting. The remaining muscle strips were rinsed for $10 \mathrm{~min}$ at $37^{\circ} \mathrm{C}$ in $3 \mathrm{~mL}$ of oxygenated KHB containing $40 \mathrm{mM}$ D-mannitol, $0.1 \%$ BSA and insulin, if previously present. Muscle strips were incubated for $20 \mathrm{~min}$ at $37^{\circ} \mathrm{C}$ in $2 \mathrm{~mL}$ of $\mathrm{KHB}$ containing $1 \mathrm{mM} 2-\left[1,2-{ }^{3} \mathrm{H}\right]$ deoxyglucose (2-DG, $300 \mu \mathrm{Ci} /$ mmol; PerkinElmer Life Sciences, Boston, MA, USA), $39 \mathrm{mM}$ [U-14C]mannitol $(0.8 \mu \mathrm{Ci} / \mathrm{mmol}$; PerkinElmer Life Sciences), $0.1 \%$ BSA and insulin, if previously present. At the end of the incubation period, the muscle strips were removed, trimmed of excess fat and connective tissue and immediately frozen in liquid nitrogen and weighed. The frozen muscles were solubilized in $0.5 \mathrm{~mL}$ of $0.5 \mathrm{~N} \mathrm{NaOH}$, and $10 \mathrm{~mL}$ of scintillation cocktail (Ultima Gold; PerkinElmer Life Sciences) was added. The specific intracellular accumulation of 2-DG was determined as described previously using mannitol to correct for the extracellular accumulation of 2-DG (Henriksen \& Halseth 1994). Glucose transport activity was measured as the intracellular accumulation of 2-DG (in $\mathrm{pmol} / \mathrm{mg}$ muscle wet weight $/ 20 \mathrm{~min}$ ).

\section{Tissue and blood collection}

After the removal of muscle tissues to determine glucose transport activity, blood was collected from the abdominal vein. Whole blood was allowed to clot and then centrifuged at $3000 \mathrm{~g}$ at $4^{\circ} \mathrm{C}$ for $20 \mathrm{~min}$ to obtain serum, which was used to determine serum triglyceride levels. Immediately after blood collection, intra-abdominal fat and the heart were collected and weighed.

\section{Analyses of signaling elements in skeletal muscle}

Muscles were homogenized in ice-cold lysis buffer: $50 \mathrm{mM}$ HEPES (pH 7.4), $150 \mathrm{mM} \mathrm{NaCl}, 1 \mathrm{mM} \mathrm{CaCl}_{2}, 1 \mathrm{mM} \mathrm{MgCl}_{2}$, $2 \mathrm{mM}$ EDTA, $10 \mathrm{mM} \mathrm{NaF}, 20 \mathrm{mM}$ sodium pyrophosphate, $20 \mathrm{mM} \beta$-glycerophosphate, $10 \%$ glycerol, $1 \%$ Triton $\mathrm{X}-100,2 \mathrm{mM} \mathrm{Na}_{3} \mathrm{VO}_{4}, 10 \mu \mathrm{g} / \mathrm{mL}$ aprotinin and leupeptin, and $2 \mathrm{mM}$ PMSF. After a 20 -min incubation on ice, the homogenates were centrifuged at $13,000 \boldsymbol{g}$ for $20 \mathrm{~min}$ at $4^{\circ} \mathrm{C}$. Aliquots of supernatant were frozen at $-80^{\circ} \mathrm{C}$, and a portion of these homogenates was used to determine total protein content (BCA method, Sigma Chemical). Proteins in the homogenates were separated on $8 \%$ or $10 \%$ polyacrylamide gels and transferred electrophoretically onto nitrocellulose paper. Protein blots of samples from incubated and non-incubated muscles were incubated with the appropriate dilution of commercially available

Published by Bioscientifica Ltd 
antibodies against phospho-insulin receptor (IR)/IGF1R (Tyr ${ }^{1158} / \mathrm{Tyr}^{\left.1162 / \mathrm{Tyr}^{1163}\right)}$ (Millipore), insulin receptor beta (IR- $\beta$ ), insulin receptor substrate 1 (IRS-1), phosphoIRS-1 (Ser ${ }^{307}$ ), phospho-Akt (Ser ${ }^{473}$ ), Akt, Akt substrate of $160 \mathrm{kDa}$ (AS160), phospho-AS160 ( $\mathrm{Thr}^{642}$ ), c-Jun $\mathrm{NH}_{2}$-terminal kinase (SAPK/JNK), phospho-SAPK/JNK (Thr $\left.{ }^{183} / \mathrm{Tyr}^{185}\right)$, p38 mitogen-activated protein kinase (MAPK) and phospho-p38 MAPK (Thr ${ }^{180} / \mathrm{Tyr}^{182}$ ). Protein blots of samples from non-incubated muscles were also incubated with commercially available antibodies against GLUT-4, GLUT-1 (Santa Cruz Biotechnology), AMPactivated protein kinase (AMPK), phospho-AMPK Thr ${ }^{172}$, angiotensin-converting enzyme 1 (ACE1) (Abcam), ACE2 (Millipore), angiotensin II receptor type 1 (AT1R) (Santa Cruz Biotechnology), AT2R (Santa Cruz Biotechnology), MAS receptor (MasR) (Santa Cruz Biotechnology) and 4-hydroxynonenal (4-HNE) (Abcam). Subsequently, all blots were incubated with goat anti-rabbit, anti-mouse or anti-goat secondary antibodies conjugated with horseradish peroxidase (IgG-HRP). All antibodies, if not specified previously, were purchased from Cell Signaling Technology. Protein bands were visualized with enhanced chemiluminescence (PerkinElmer Life Sciences) on a C-Digit Blot Scanner (LI-COR Biotechnology, Lincoln, NE, USA) with Image Studio Software, version 3.1 for the quantitative analysis of band intensities.

\section{Statistical analysis}

All values are expressed as the means \pm S.E. Differences among groups were determined by one-way ANOVA with Tukey's post hoc test. A two-way ANOVA was used to analyze the effects of two variables followed by Tukey's post hoc test for multiple comparisons. Data lacking normal distribution and/or equal variance were mathematically transformed by the logarithm or square root to achieve normality and equal variance before oneor two-way ANOVA was being tested. Statistical analyses were performed using SigmaPlot 12.0 (Systat Software, San Jose, CA, USA). A value of $P<0.05$ was considered to be statistically significant.

\section{Results}

\section{Effects of chronic ANGIl infusion on body weight, tissue weight, food and water intake}

The body weights, abdominal fat weights, heart weights and food and water intakes of the SHAM and
ANGII-100 groups were comparable (Fig. 1 and Table 1). Compared to other groups, ANGII-500 infusion led to significant decreases in body weight $(\sim 15 \%)$ (Fig. 1A) and the abdominal fat weight-to-body weight ratio $(\sim 25 \%)$, as well as an increase in the heart weight-to-body weight ratio (17-20\%) (Table 1). The amounts of daily food intake for the ANGII-500 group rapidly decreased $(P<0.05)$ by $35 \%$ and continued at this level throughout the experiment (Fig. 1B), whereas the volume of water intake increased $(P<0.05)$ (Fig. 1C).
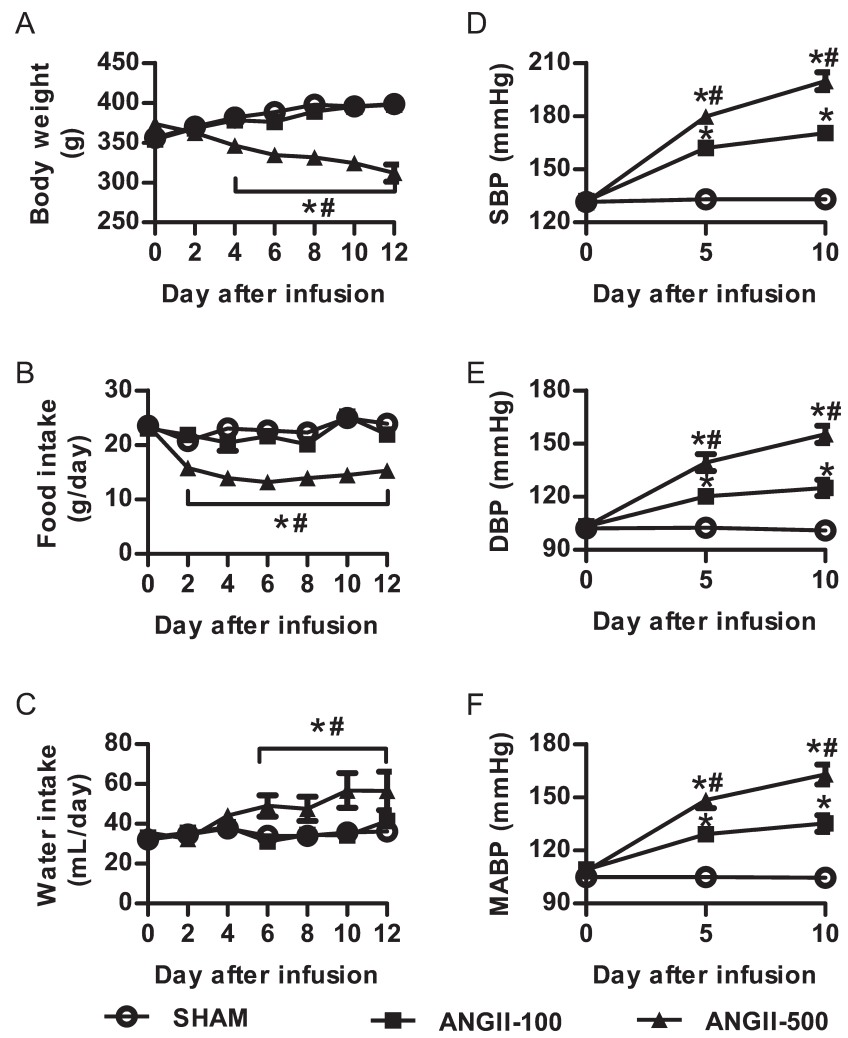

Figure 1

Body weights, food and water intake and blood pressure responses after chronic ANGII infusion. Body weights (A), and food (B) and water (C) intake of rats receiving normal saline infusion (SHAM) and rats receiving ANGII infusion (ANGII-100 and ANGII-500). Body weights and food and water intake were monitored regularly during the experimental period. Systolic blood pressure (SBP; D), diastolic blood pressure (DBP; E) and mean arterial blood pressure (MABP; F) were measured from the tail of each rat using a CODA non-invasive blood pressure device. Values are the means \pm S.E. for 10 animals/group. There was a significant main effect of time on body weight in all groups, food and water intake in the ANGII-500 group and SBP, DBP and MABP in the ANGII-100 and ANGII-500 groups. A significant main effect of ANGII treatment was observed. Post hoc analysis indicated ${ }^{*} P<0.05$ vs SHAM group; $\# P 0.05$ vs ANGII-100 group.

Published by Bioscientifica Ltd. 
Table 1 Final body weights, heart weights, fat weights, heart rate, fasting plasma glucose and insulin levels and serum triglycerides after SHAM and ANGII infusion at 100 and $500 \mathrm{ng} / \mathrm{kg} / \mathrm{min}$.

\begin{tabular}{|c|c|c|c|}
\hline & SHAM & ANGII-100 & ANGII-500 \\
\hline BW (g) & $420 \pm 3.94$ & $406 \pm 6.90$ & $351 \pm 11.94 *$ \\
\hline $\mathrm{HW}(\mathrm{g})$ & $1.55 \pm 0.12$ & $1.45 \pm 0.18$ & $1.42 \pm 0.15^{*}, \#$ \\
\hline HW/kg BW & $3.69 \pm 0.30$ & $3.57 \pm 0.46$ & $4.05 \pm 0.81 *$ \\
\hline $\mathrm{FW}(\mathrm{g})$ & $17.1 \pm 1.1$ & $16.8 \pm 1.0$ & $10.3 \pm 1.2^{*, \#}$ \\
\hline FW/kg BW & $40.7 \pm 2.75$ & $41.4 \pm 3.16$ & $29.3 \pm 3.24 *$ \\
\hline HR (bpm) & $414 \pm 12.9$ & $429 \pm 7.5$ & $420 \pm 12.8$ \\
\hline $\begin{array}{l}\text { Plasma glucose } \\
\text { (mg/dL) }\end{array}$ & $139 \pm 11$ & $135 \pm 9$ & $128 \pm 15$ \\
\hline $\begin{array}{l}\text { Plasma insulin } \\
(\mu \mathrm{U} / \mathrm{mL})\end{array}$ & $27.1 \pm 5.0$ & $23.9 \pm 7.1$ & $23.0 \pm 6.1$ \\
\hline $\begin{array}{l}\text { Serum triglyceride } \\
(\mathrm{mg} / \mathrm{dL})\end{array}$ & $32.2 \pm 3.1$ & $33.3 \pm 4.9$ & $51.3 \pm 3.3^{*, \#}$ \\
\hline
\end{tabular}

Values are the means \pm S.E. for $8-10$ animals per group. $* P<0.05$ vs SHAM group; $\# P<0.05$ vs ANGII- 100 group. BW, body weight; FW, fat weight; HR, heart rate; HW, heart weight.

\section{Blood pressure, heart rate, fasting plasma glucose and insulin and serum triglycerides}

The systolic, diastolic and mean arterial blood pressures of the SHAM and ANGII-treated rats were determined before and after implantation of the osmotic minipump (Fig. 1D, E and F). The arterial pressures were relatively unchanged in the SHAM group, whereas ANGII-100 infusion gradually increased the systolic, diastolic and mean arterial blood pressures $(P<0.05)$ over the experimental period. When compared to ANGII-100, ANGII-500 significantly increased blood pressure to a greater extent. These results indicate that ANGII induced hypertensive conditions in a dose-dependent manner. No significant differences in heart rate, fasting plasma glucose and insulin levels among the groups were detected, whereas ANGII-500 infusion increased $(P<0.05)$ the serum triglyceride concentrations when compared with other groups (Table 1 ).

\section{Glucose tolerance and insulin sensitivity after chronic ANGII infusion}

The profiles of plasma glucose and insulin levels during OGTT are shown in Fig. 2. ANGII-100 infusion led to a significant increase in plasma insulin level at the 15-min time point with a trending increase in the area under the curve (AUC) for insulin (Fig. 2B and D), whereas ANGII500 administration resulted in significant increases in plasma glucose levels at the 15-, 60- and 120-min time points (Fig. 2A) and glucose AUC (Fig. 2C) when compared
A

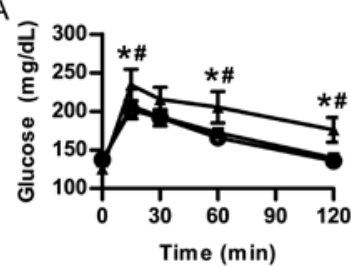

B

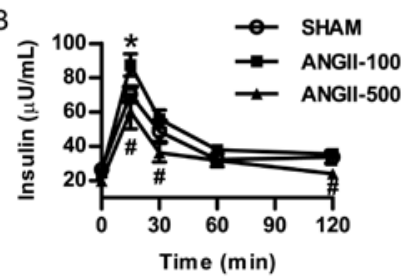

C

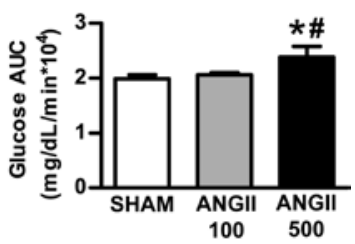

D

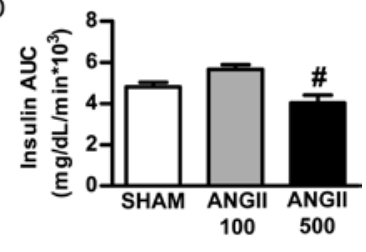

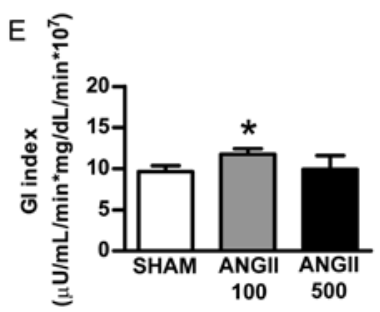

Figure 2

Glucose tolerance and insulin sensitivity after chronic ANGII infusion. Plasma glucose $(A)$ and plasma insulin (B) responses during OGTT in rats receiving normal saline infusion (SHAM) and rats receiving ANGII infusion (ANGII-100 and ANGII-500). The glucose AUC (C), insulin AUC (D) and G-I index (E) were calculated to represent whole-body insulin sensitivity. Values are the means \pm S.E. for $8-10$ animals/group. There was a significant main effect of time on the levels of plasma glucose $(A)$ and insulin (B) in all groups. A significant main effect of ANGII treatment was observed. Post hoc analysis indicated ${ }^{*} P<0.05$ vs SHAM group; ${ }^{P}<0.05$ vs ANGII-100 group.

to other groups. Despite the hyperglycemic response, however, insulin levels in the ANGII-500 group at the 15-, 30- and 120-min time points, and insulin AUC were significantly lower when compared with the ANGII-100 group (Fig. 2B). The glucose-insulin index (G-I index) is defined as the product of glucose AUC and insulin AUC and is inversely related to an increase in wholebody peripheral insulin sensitivity (Cortez et al. 1991). The G-I index of the ANGII-100 group was significantly higher than that in the SHAM group. Due to the opposing responses in terms of the plasma glucose and insulin levels, the G-I index in the ANGII-500 group was not changed when compared with that in SHAM.

\section{Effect of chronic ANGII administration on soleus muscle glucose uptake}

Skeletal muscle glucose uptakes in the absence and presence of insulin are depicted in Fig. 3A, and the 
A
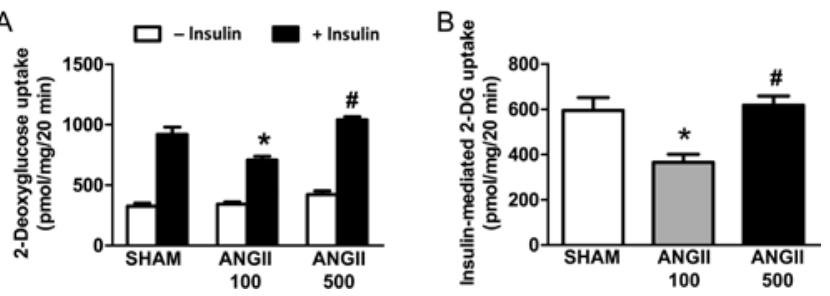

Figure 3

Effects of chronic ANGII administration on soleus muscle glucose transport. In vitro rates of 2-DG uptake in the absence and presence of insulin $(2 \mathrm{mU} / \mathrm{mL})(A)$ and net increases above basal rates of 2-DG transport activities due to insulin (B) in soleus muscles of rats receiving normal saline infusion (SHAM) and rats receiving ANGII infusion (ANGII-100 and ANGII-500). Values are the means \pm S.E. for 8-10 animals/ group. There was a significant main effect of insulin on 2-DG uptake. A significant main effect of ANGIl treatment was observed. Post hoc analysis indicated ${ }^{*} P<0.05$ vs SHAM group; $\# P<0.05$ vs ANGII-100 group.

insulin-induced glucose uptakes above basal levels are illustrated in Fig. 3B. When compared to the SHAM group, insulin-stimulated and insulin-mediated glucose uptakes in the muscles of ANGII-100-treated rats were significantly decreased by $33 \%$ and $39 \%$, respectively. ANGII-500 infusion resulted in a significant increase in insulin-stimulated glucose uptake above the values of the ANGII-100 group (Fig. 3A). Insulin-mediated glucose uptake of the ANGII-500 group was comparable to that of SHAM but was significantly higher $(\sim 40 \%)$ than that of the ANGII-100 group (Fig. 3B).

\section{Insulin signaling elements, GLUT-1 and GLUT-4 abundance in skeletal muscle}

To assess the impacts of chronic ANGII infusion on insulin signaling elements, the expression and phosphorylation levels of IR- $\beta$, IRS- 1 , Akt and AS160 were determined by immunoblot analysis in non-incubated soleus muscle. No significant changes in these proteins were observed among experimental groups (Fig. 4). Nevertheless, we found that GLUT-1 protein expression was comparable among groups, whereas ANGII-100 and ANGII-500 infusion brought about significant reductions in GLUT-4 protein abundance by $40 \%$ and $25 \%$, respectively (Fig. 5A). To assess the ability of insulin to activate the signaling elements in the insulin signaling pathway, the phosphorylation and expression levels of IR- $\beta$, IRS-1, Akt and AS160 in the soleus strips incubated in the absence and presence of insulin were determined (Fig. 5B). There were no significant differences in the expression of IR- $\beta$, IRS-1, Akt and AS160 and the phosphorylation of IR- $\beta$ among groups. Compared to SHAM, however, a significant increase in insulin-stimulated phosphorylation of IRS-1 $\mathrm{Ser}^{307}$ and decreases in insulin-stimulated phosphorylation of Akt Ser ${ }^{473}$ and AS160 Thr $^{642}$ were observed in the ANGII-100 group. Interestingly, defects in the insulin signaling elements presented in the ANGII-100 group were not detected in the ANGII-500 group.

\section{Effect of ANGII treatment on ROS generation and the MAPK pathway}

4-hydroxynonenal (4-HNE), a product of lipid peroxidation, has been implicated in the etiology of pathological alterations under oxidative stress and is considered to be a reliable index of ROS (Browning \& Horton 2004, Wei et al. 2008). We found that the 4-HNE levels in the skeletal muscle of the ANGII-100 and ANGII500 groups were $44 \%$ and $105 \%$ above that of the SHAM group, respectively (Fig. 6A). It appears that ANGII dose is

\begin{tabular}{|c|c|c|c|c|c|}
\hline & SHAM & ANGII-100 & ANGII-500 & $P$-value & $\begin{array}{l}\text { Representative } \\
\text { Western blot }\end{array}$ \\
\hline p-IR- $\beta$ & $1.00 \pm 0.07$ & $1.24 \pm 0.18$ & $1.17 \pm 0.20$ & 0.78 & 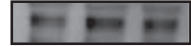 \\
\hline IR- $\beta$ & $1.00 \pm 0.02$ & $1.09 \pm 0.09$ & $0.98 \pm 0.11$ & 0.75 & $-\cdots$ \\
\hline p-IRS-1 Ser ${ }^{307}$ & $1.00 \pm 0.04$ & $1.32 \pm 0.24$ & $1.22 \pm 0.19$ & 0.62 & 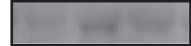 \\
\hline IRS-1 Ser ${ }^{307}$ & $1.00 \pm 0.12$ & $1.26 \pm 0.22$ & $1.10 \pm 0.14$ & 0.66 & $--1=$ \\
\hline p-Akt $\operatorname{Ser}^{473}$ & $1.00 \pm 0.01$ & $1.04 \pm 0.08$ & $0.9 \pm 0.05$ & 0.89 & --- \\
\hline Akt Ser ${ }^{473}$ & $1.00 \pm 0.11$ & $1.18 \pm 0.11$ & $1.07 \pm 0.08$ & 0.75 & --- \\
\hline p-AS160 Thr ${ }^{642}$ & $1.00 \pm 0.07$ & $1.14 \pm 0.13$ & $1.05 \pm 0.09$ & 0.79 & --- \\
\hline AS160 Thr ${ }^{642}$ & $1.00 \pm 0.12$ & $1.06 \pm 0.10$ & $1.05 \pm 0.10$ & 0.69 & 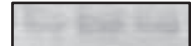 \\
\hline
\end{tabular}

\section{Figure 4}

Expressions of insulin signaling protein including IR- $\beta$ Tyr ${ }^{1158} / \mathrm{Tyr}^{1162 / T y} \mathrm{r}^{1163}$ phosphorylation ( $\left.\mathrm{p}-\mathrm{IR}-\beta\right)$, IR- $\beta$, IRS-1 Ser ${ }^{307}$ phosphorylation ( $p$-IRS-1 Ser ${ }^{307}$ ), IRS-1, Akt Ser473 phosphorylation (p-Akt Ser ${ }^{473)}$, Akt, AS160 Thr642 phosphorylation (p-AS160 Thr642) and AS160 in non-incubated soleus muscle of SHAM and ANGII infusion at 100 and $500 \mathrm{ng} /$ $\mathrm{kg} / \mathrm{min}$. Values are means \pm S.E. for $6-8$ animals per group. http://joe.endocrinology-journals.org DOI: $10.1530 / \mathrm{JOE}-16-0579$ (c) 2017 Society for Endocrinology Printed in Great Britain 
A

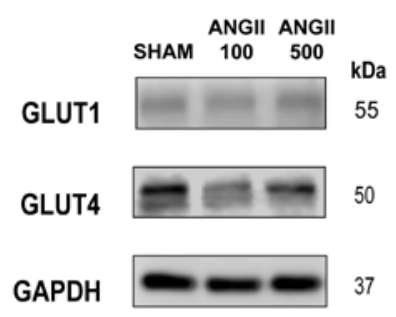

B
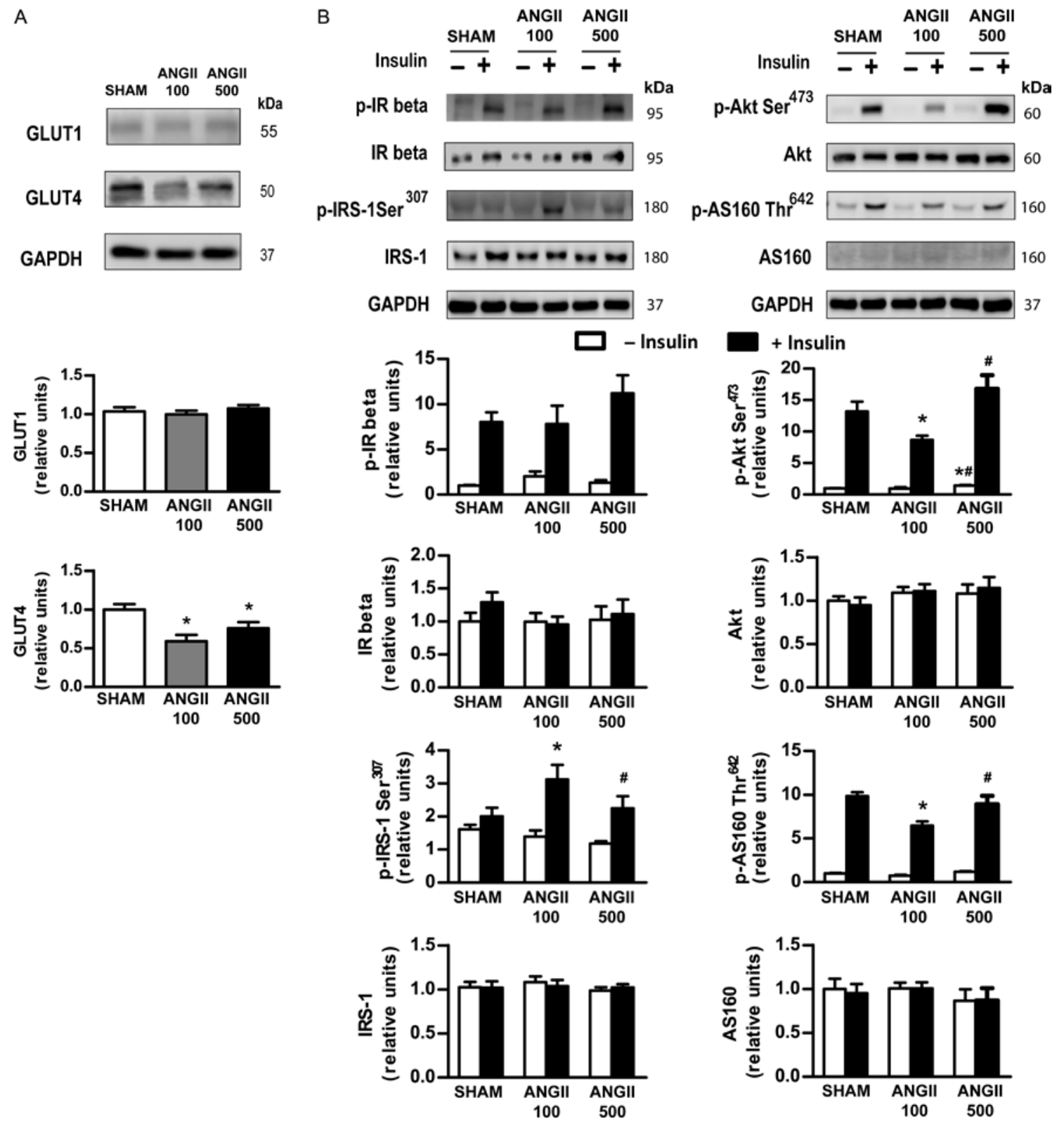

Figure 5

GLUT-1 and GLUT-4 abundance and insulin signaling elements in skeletal muscle. GLUT-1 and GLUT-4 protein expression (A) in non-incubated soleus muscle that were obtained from rats receiving normal saline infusion (SHAM) and rats receiving ANGII infusion (ANGII-100 and ANGII-500). Insulininduced expression and phosphorylation of insulin signaling elements in incubated soleus muscles in the absence or the presence of insulin ( $2 \mathrm{mU} / \mathrm{mL}$ ) (B). Proteins were determined by immunoblot analysis and were normalized to GAPDH. Data are presented as the fold change over the SHAM. Representative bands from the C-Digit Blot Scanner are displayed at the top of the figure. Values are the means \pm s.E. for $6-8$ animals/group. There was a significant main effect of insulin on phosphorylation of insulin signaling elements (B). A significant main effect of ANGII treatment was observed. Post hoc analysis indicated $* P<0.05$ vs SHAM group; $\# P<0.05$ vs ANGII-100 group.

one factor that determines the degree of ROS generation. The expression and phosphorylation levels of p38 MAPK and SAPK/JNK were determined in soleus muscle strips to examine whether they were affected by chronic ANGII infusion. There were no significant changes in the protein expression. Compared with SHAM, ANGII-100 and ANGII500 infusion enhanced $(P<0.05)$ the phosphorylation levels of p38 MAPK by 3- to 4-fold, whereas ANGII-500 also increased SAPK/JNK by $21 \%$ (Fig. 6B). To investigate whether these MAPKs were associated with alterations in insulin-stimulated glucose transport activity, the expression and phosphorylation levels of these MAPKs were assessed in muscle strips incubated in the absence or presence of insulin. We found that the patterns of 
A

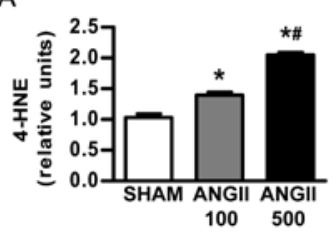

B
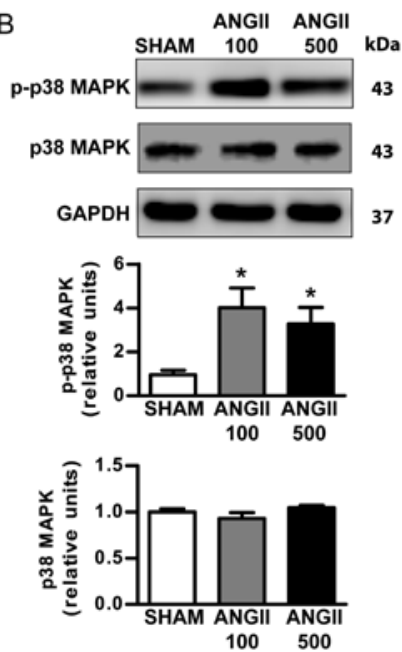
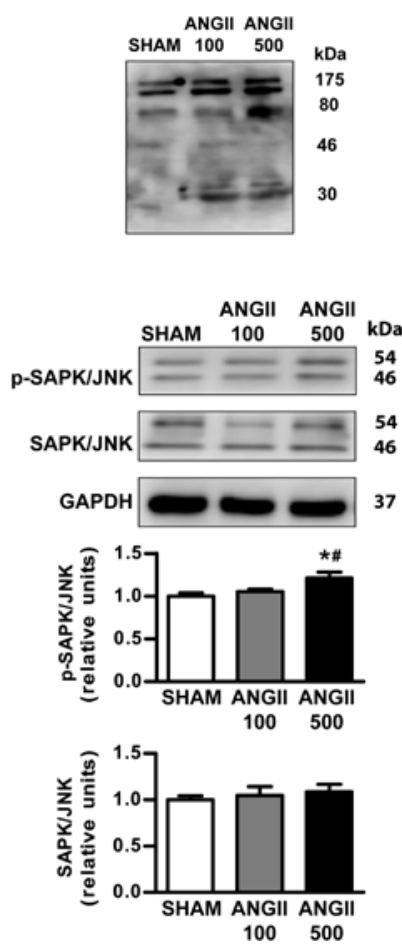

C
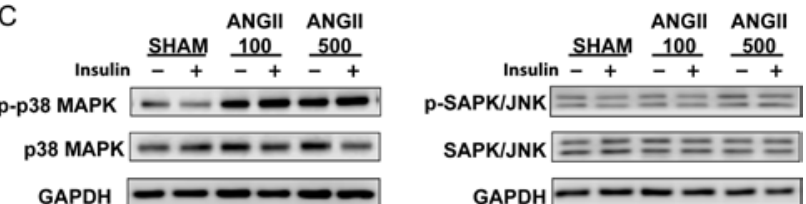
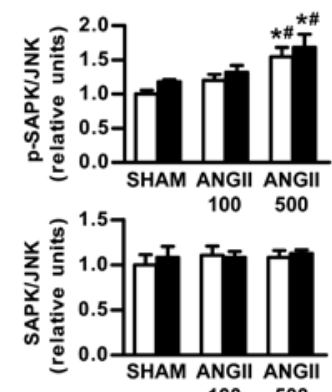

Figure 6

Effects of ANGII treatment on ROS generation and the MAPK pathway. 4-HNE, the marker of oxidative stress, induced by ANGII infusion (A). Expression of the signaling proteins SAPK/JNK, phosphorylated SAPK/JNK (Thr 183/Tyr ${ }^{185}$ ) (p-SAPK/JNK), p38 MAPK and phosphorylated p38 MAPK (Thr180/Tyr ${ }^{182}$ ) (p-p38 MAPK) in non-incubated soleus muscle (B). Insulin-induced expression of SAPK/JNK, p-SAPK/JNK, p38 MAPK and p-p38 MAPK in soleus muscles incubated in the absence or the presence of insulin $(2 \mathrm{mU} / \mathrm{mL})(C)$ as determined by immunoblot analysis. Data are presented as the fold change over the SHAM (normal saline infusion) group. Representative bands from the C-Digit Blot Scanner are displayed at the right side (4-HNE) and at the top of the figure. Values are the means \pm s.E. for 6-8 animals/group. No significant main effects of insulin were detected on all variables in (C). A significant main effect of ANGII treatment was observed. Post hoc analysis indicated ${ }^{*} P<0.05$ vs SHAM group; $\# P<0.05$ vs ANGII-100 group.

changes for p38 MAPK and SAPK/JNK observed in the non-incubated and incubated muscle strips were similar, and insulin did not enhance the levels of these MAPKs (Fig. 6C).

\section{Expression of AMPK, AT1R, AT2R, ACE1, ACE2 and MasR in skeletal muscle}

Increased glucose transport activity can be mediated by other molecules, such as AMPK and the ACE2/ANG(1-7)/ MasR axis, which are independent of insulin (Ruderman et al. 2013, Echeverria-Rodriguez et al. 2014). We found that a reduction in the phosphorylation levels of AMPK Thr ${ }^{172}$ was observed only in the ANGII-100 group (Fig. 7A). ANGII-100 and ANGII-500 increased ACE2 protein expression above the SHAM level by 31\% and 85\%, respectively (Fig. 7C). Although ANGII-100 infusion did not affect the expression of MasR protein, ANGII-500 significantly enhanced $(P<0.05)$ MasR by $68 \%$ (Fig. 7C). We also showed that the expression of proteins in the classic RAS including AT1R,
AT2R and ACE1 was not different among experimental groups (Fig. 7B).

\section{Discussion}

The present study demonstrated that chronic infusion with ANGII-100 induced skeletal muscle insulin resistance, which was associated with decreases in total GLUT-4 abundance, phosphorylation of AMPK Thr172 and insulin-stimulated phosphorylation of Akt Ser ${ }^{473}$ and AS160 Thr ${ }^{642}$ with increases in oxidative stress markers, phosphorylation of p38 MAPK Thr ${ }^{180} / \mathrm{Tyr}^{182}$ and insulinstimulated phosphorylation of IRS-1 $\mathrm{Ser}^{307}$ (negatively regulates IRS function). Importantly, the main finding of this study provided novel information that not only did chronic ANGII-500 infusion fail to aggravate insulin resistance as anticipated, but insulin-stimulated skeletal muscle glucose transport activity of the ANGII-500 group was comparable to the level of the SHAM group. Intriguingly, insulin action on glucose transport activity, 
A
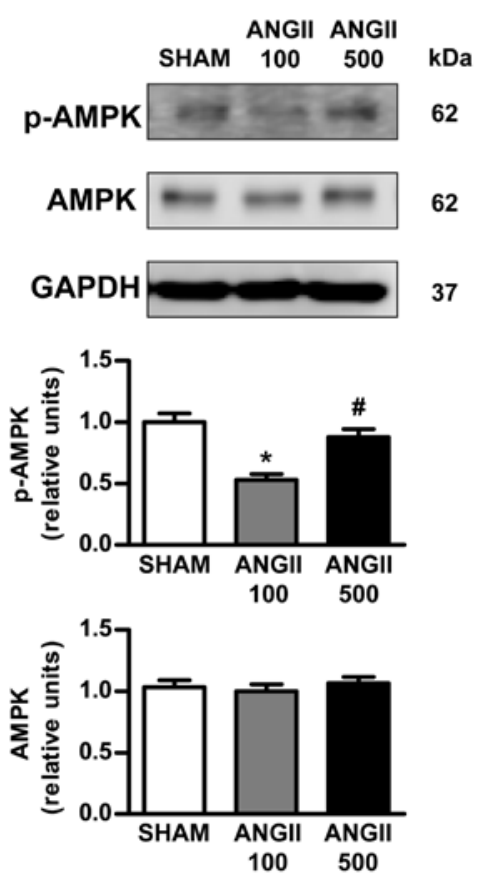

B
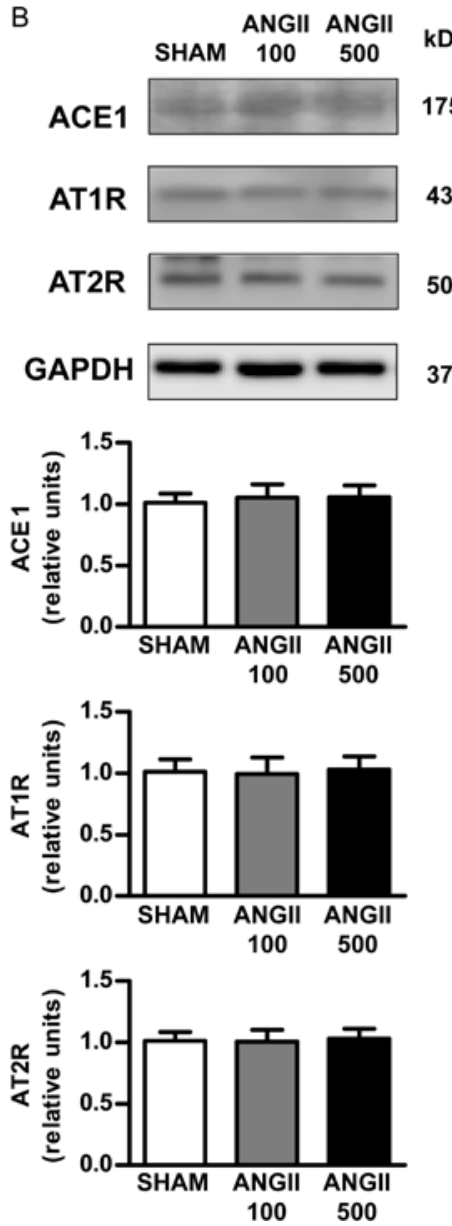

C
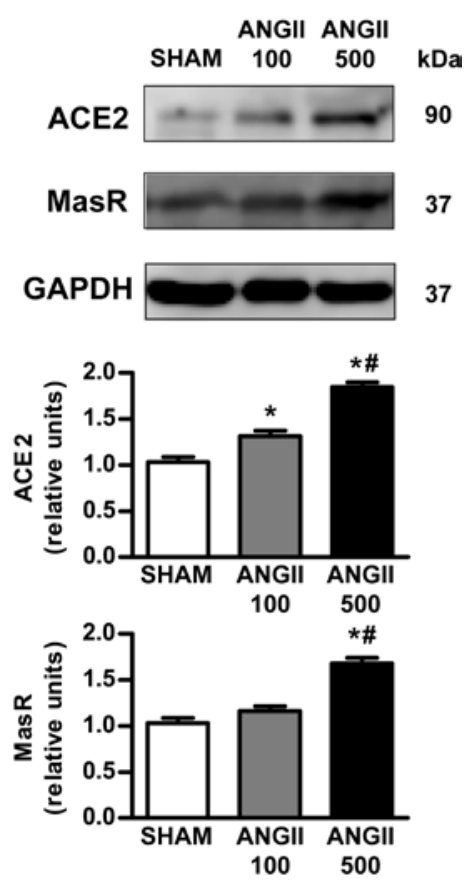

Figure 7

Effects of ANGII infusion on AMPK, ACE1, ACE2, AT1R, AT2R and MAS receptor in skeletal muscle. Effects of ANGII infusion on the expression of AMPK and phosphorylated AMPK Thr172 (p-AMPK Thr ${ }^{172}$ ) (A) and ACE1, AT1R and AT2R (B) and ACE2 and MAS receptor (MasR) (C) in non-incubated soleus muscle. Proteins were determined by immunoblot analysis and were normalized to GAPDH. Data are presented as the fold change over the SHAM (normal saline infusion) group. Representative bands from the C-Digit Blot Scanner are displayed at the top of the figure. Values are the means \pm s.E. for $6-8$ animals/group. ${ }^{*} P<0.05$ vs SHAM group; ${ }^{*} P<0.05$ vs ANGII-100 group.

the phosphorylation of IRS-1 Ser ${ }^{307}$, Akt Ser 473 and AS160 $\mathrm{Thr}^{642}$ and the phosphorylation of AMPK Thr ${ }^{172}$ in skeletal muscle of the ANGII-500 and SHAM groups was comparable, whereas ANGII-500 additionally increased ACE2 and MasR protein expression above SHAM group levels. At the whole-body level, rats treated with ANGII100 were characterized by phenotypic features of nonobese metabolic syndrome, whereas ANGII-500-treated rats exhibited diabetes-like symptoms.

Rodents infused with a broad range of ANGII concentrations (10-1440 $\mathrm{ng} / \mathrm{kg} / \mathrm{min})$ via implantable osmotic minipumps have been used as a valuable experimental model to investigate the pathology of hypertension and associated conditions (for a review, see Qin (2008)). The severity of hypertension, diabetes and cardiovascular dysfunction has been reportedly associated with plasma ANGII levels (Catt et al. 1969, Staroukine et al. 1984, Nicola et al. 2001). Chronic ANGII infusion at $100 \mathrm{ng} / \mathrm{kg} / \mathrm{min}$, which has been most often used, led to several features of insulin resistance syndrome such as hypertension, hypertriglyceridemia and impaired insulin sensitivity (Ran et al. 2004, 2005). Despite this, it remains unknown how insulin action on skeletal muscle glucose transport is affected when plasma ANGII levels rise to a higher pressor dose, a condition observed in individuals with severe hypertension and impaired cardiac function. In fact, only two studies have investigated the causal role of ANGII infusion in the development of skeletal muscle insulin resistance. The investigators chronically infused ANGII at 100 and $200 \mathrm{ng} / \mathrm{kg} / \mathrm{min}$ (Ogihara et al. 2002, Lastra et al. 2013), and their results were contradictory. Impaired insulin-stimulated glucose transport activity 
A ANGII infusion at $100 \mathrm{ng} / \mathrm{kg} / \mathrm{min}$
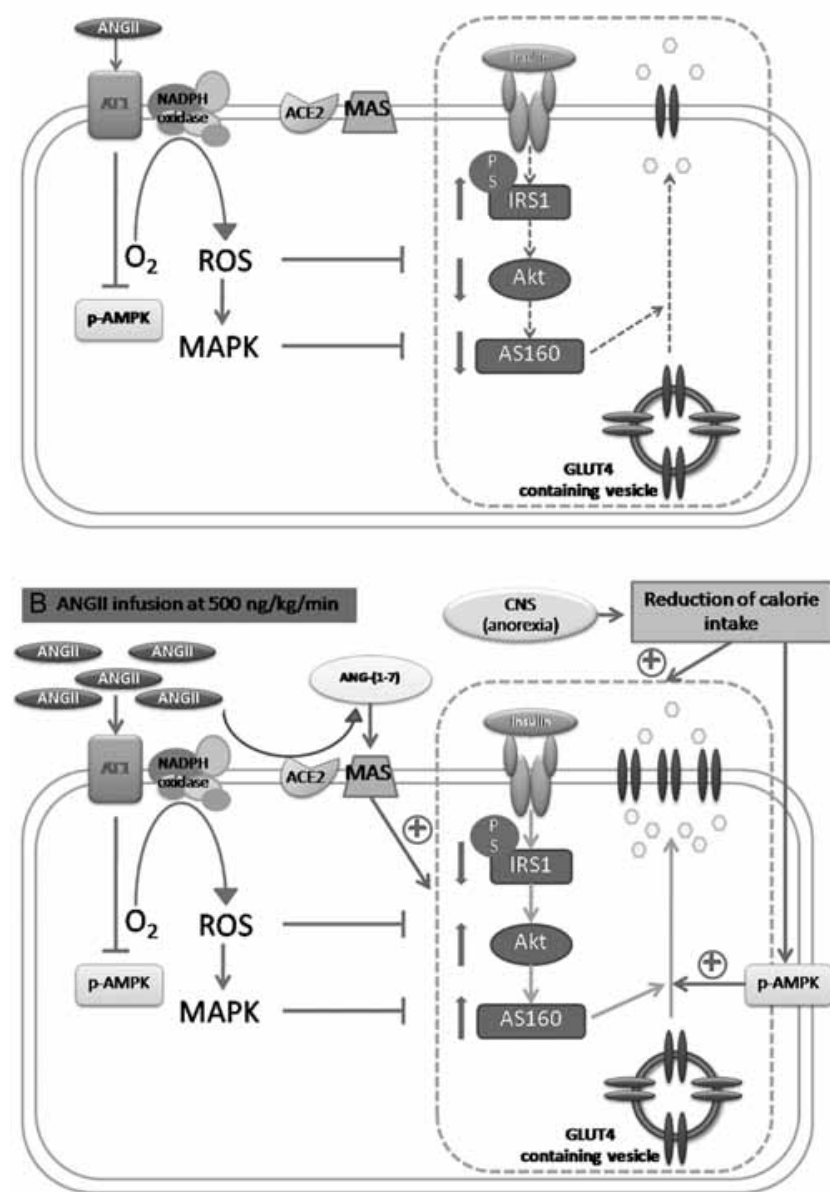

Figure 8

Proposed mechanisms underlying the effects of ANGII on the skeletal muscle glucose transport system. ANGII-100 activates NADPH oxidase to generate reactive oxygen species (ROS) and enhances MAPK, resulting in diminished insulin-stimulated insulin signaling and glucose transport activity (A). ANGII-500 induces a reduction in caloric intake and activates AMPK phosphorylation. Excessive ANGII enhances protein expression in the ACE2/ANG(1-7)/MasR axis (B).

of skeletal muscle in rats was associated with (1) enhanced insulin signaling elements, including tyrosine phosphorylation of IRS- 1 and IRS- 2 and the activation of PI3-K and Akt after chronic intravenous ANGII infusion at $100 \mathrm{ng} / \mathrm{kg} / \mathrm{min}$ (Ogihara et al. 2002) and (2) diminished phosphorylation of Akt and AS160 after chronic subcutaneous infusion with ANGII at $200 \mathrm{ng} / \mathrm{kg} /$ min (Lastra et al. 2013). The present study demonstrates that rats that received chronic subcutaneous ANGII infusion at $100 \mathrm{ng} / \mathrm{kg} / \mathrm{min}$ exhibited gradually elevated blood pressure and insulin resistance of skeletal muscle glucose transport activity with multiple post-receptor defects, including increased IRS-1 Ser ${ }^{307}$ phosphorylation, decreased phosphorylation of Akt Ser ${ }^{473}$ and AS160 Thr ${ }^{642}$ and diminished GLUT-4 protein abundance (Fig. 8A). Thus, our results are consistent with those reported by Lastra and coworkers (Lastra et al. 2013), and we speculate that the ANGII dose and route of administration may explain the paradoxical observations between our study and Ogihara and coworkers (Ogihara et al. 2002).

Reactive oxygen species (ROS) have been implicated as a link between ANGII and insulin resistance (Henriksen et al. 2011). Previous studies in cultured L6 myotubes revealed that ANGII activated ROS and impaired insulin signaling molecules (Wei et al. 2006, 2008). Moreover, skeletal muscle insulin resistance in transgenic TG(mRen2)27 (Sloniger et al. 2005) and hypertensive Dahl salt-sensitive rats (Zhou et al. 2015) was associated with significant increases in oxidative stress and elevated tissue ANGII levels. It has been demonstrated that the mitogen-activated protein kinase (MAPK) pathway, in particular p38 MAPK and SAPK/JNK, has an important role in ROS-induced insulin resistance, as ROS activates these kinases, which negatively modulate insulin-stimulated glucose transport activity (Kim et al. 2006, Archuleta et al. 2009, Vichaiwong et al. 2009, Santos et al. 2012). The present study demonstrated that infusion with ANGII100 and ANGII-500 enhanced ROS formation and MAPK activity in the soleus muscle in a dose-dependent manner and increased ROS formation and MAPK activity in the ANGII-100 group was associated with skeletal muscle insulin resistance. Nevertheless, unlike the findings in the ANGII-100 group, further increases in ROS generation and MAPK activity in the ANGII-500 group did not compromise insulin action on glucose transport activity. Unexpectedly, we found that ANGII-500 infusion led to normalization of the insulin-stimulated phosphorylation of IRS-1 Ser ${ }^{307}$, Akt Ser ${ }^{473}$, AS160 Thr ${ }^{642}$ and skeletal muscle glucose transport activity to the levels of the SHAM group.

There are a few possible mechanisms that may explain our findings from the ANGII-500 group. First, it is well documented that a reduction in caloric intake, such as a moderate degree of calorie restriction, can enhance glucose uptake and insulin signaling elements in rat skeletal muscle (Park et al. 2005, Speakman \& Mitchell 2011, Prasannarong et al. 2012b). A series of experiments have shown that phosphorylation of Akt, especially on Akt2, is essential for the favorable effect of calorie restriction on glucose uptake (Carrie E McCurdy et al. 2003, McCurdy \& Cartee 2005, Wang et al. 2016). In this study, the average food intake in the ANGII-500 group was significantly lower than other groups by $25-35 \%$. 
Thus, our findings are consistent with a notion that reduced caloric intake could be a contributing factor that enhanced skeletal muscle insulin action and signaling in the ANGII-500 group. Second, it has been shown that ANGII inactivated the activity of AMPK (Yoshida et al. 2009, Deji et al. 2012), a sensor of cellular energy status that can stimulate GLUT-4 translocation to the plasma membrane independent of insulin. Our data also showed that phosphorylation of AMPK was indeed inhibited in the ANGII-100 group, and we found that AMPK Thr172 in the skeletal muscle of the ANGII-500 group was maintained to the level of the SHAM group. As the AMPK system can be altered when cellular energy homeostasis is disturbed, such as the disturbance occurring during calorie restriction (Hardie 2003, Towler \& Hardie 2007, Wang et al. 2012), we speculate that intact levels of AMPK $\mathrm{Thr}^{172}$ may be essential to maintain glucose transport activity. Third, evidence for the counter-regulatory role of the ACE2/ANG(1-7)/MasR axis against the action of ANGII via the ACE/ANGII/AT1R axis is emerging (Giani et al. 2009, Echeverria-Rodriguez et al. 2014, Santos \& Andrade 2014). The essential role of ACE2, which cleaves ANGII into ANG(1-7), as a negative regulator of the RAS in several disease conditions has been recognized (Fernandes et al. 2010, Song et al. 2013, Takeda et al. 2013). Studies have shown that activity of the ACE2/ ANG(1-7)/MasR axis that counteracts ANGII signaling occurs via a MasR-dependent mechanism. For instance, a selective antagonist of MasR completely prevented the positive effects of ANG(1-7) on insulin-mediated glucose transport (Prasannarong et al. 2012a). Importantly, ACE2 and ANG(1-7) concentrations were increased when AT1R was inhibited (Zimmerman et al. 2014). Thus, we hypothesized that ANGII-500 administration provided excessive available ANGII, which became a substrate for the ACE2/ANG(1-7)/MasR axis (Fig. 8B). Consequently, the enhanced ACE2 and MasR protein expression contributed to the normalization of insulin action and signaling. Importantly, the present study has provided new information that the expression of proteins in the classical RAS including AT1R, AT2R and ACE1 in skeletal muscle was not affected by chronic ANGII infusion.

The impact of ANGII on GLUT-4 protein expression has been addressed in a limited number of studies. An earlier report found that ANGII-100 infusion induced skeletal muscle insulin resistance without affecting total GLUT-4 content (Ogihara et al. 2002). In contrast, several studies showed that treatment with an ACE or AT1R antagonist increased GLUT-4 protein expression and attenuated insulin resistance in rat skeletal muscle (Jacob et al. 1996, Henriksen et al. 2001). Additionally, GLUT-4 protein expression and its transcriptional factors were reduced in the skeletal muscle of ACE2-knockout mice (Takeda et al. 2013). In the present study, we found that chronic ANGII infusion resulted in a significant reduction in total GLUT-4 abundance. Thus, our findings provide evidence to support the concept that ANGII can negatively modulate GLUT-4 protein expression.

A further novel finding from the present study is the observation that rats chronically infused with ANGII100 and ANGII-500 exhibited multiple differences in metabolic features. In addition to hypertension and skeletal muscle insulin resistance, rats treated with ANGII-100 developed impaired glucose tolerance as indicated by the higher G-I index. Glucose intolerance in these rats occurred without significant changes in energy intake, abdominal fat weight and body weight or serum triglyceride levels when compared to SHAM animals. Thus, our observations suggest that chronic ANGII-100 infusion induced a number of phenotypic characteristics representing non-obese insulin resistance syndrome. On the other hand, ANGII-500-treated rats exhibited lower energy intake, less abdominal fat accumulation and body weight, an aggravated degree of hypertension and hypertriglyceridemia. Importantly, compensatory hyperinsulinemia did not occur, even when hyperglycemia was observed during OGTT. Our findings confirmed the results demonstrated by Müller and coworkers that a high dose of chronic ANGII infusion brought about hyperglycemia and hypoinsulinemia during an oral glucose tolerance test (Müller et al. 2007). Because ANGII was reported to participate in the development of pancreatic fibrosis associated with pancreatic cell apoptosis (Carlsson et al. 1998, Osborn et al. 2011), our results are consistent with the notion that chronic ANGII500 administration impaired beta cell function, which led to the conditions mimicking type 1 diabetes.

It should be noted that lack of plasma ANGII measurements due to technical problems is a limitation to this study. Nevertheless, other studies employing the same osmotic minipump model have reported that plasma ANGII concentrations in rats infused with ANGII at $100 \mathrm{ng} / \mathrm{kg} / \mathrm{min}$ and $500 \mathrm{ng} / \mathrm{kg} / \mathrm{min}$ were 2 -fold and 4- to 6-fold higher than the control levels, respectively (Cassis et al. 1998, Huang et al. 2010). Our observation that hypertensive conditions were additionally aggravated in the ANGII-500 group also implies higher ANGII levels in the ANGII-500 group.
Published by Bioscientifica Ltd 


\section{Conclusion}

The present investigation demonstrates for the first time that ANGII at a commonly used dose (ANGII-100) and at a higher pressor dose (ANGII-500) differentially modulates metabolic features. In skeletal muscle, ANGII-100 induced skeletal muscle insulin resistance and impaired the insulin signaling pathway, whereas ANGII-500 normalized insulin-stimulated skeletal muscle glucose transport activity and other signaling molecules to SHAM levels. At the whole-body level, ANGII-100-treated rats were characterized by certain phenotypic manifestations that described non-obese insulin resistance syndrome, whereas ANGII-500-treated rats displayed diabetes-like features. Therefore, our findings support the notion that ANGII is one of the contributing factors in the development of insulin resistance and diabetes in hypertensive patients. Additionally, the evidence presented in this study suggests that ANGII doses should be cautiously taken into consideration when ANGII is used to investigate the pathology of diseases in animal models.

\section{Declaration of interest}

The authors declare that there is no conflict of interest that could be perceived as prejudicing the impartiality of the research reported.

\section{Funding}

This work was supported by grants from the Faculty of Science, Mahidol University, and The Thailand Research Fund (TRF) through the Royal Golden Jubilee (RGJ) Ph.D. Program (Grant PHD/0228/2552).

\section{References}

Archuleta TL, Lemieux AM, Saengsirisuwan V, Teachey MK, Lindborg KA, Kim JS \& Henriksen EJ 2009 Oxidant stress-induced loss of IRS-1 and IRS-2 proteins in rat skeletal muscle: role of p38 MAPK. Free Radical Biology and Medicine 47 1486-1493. (doi:10.1016/j. freeradbiomed.2009.08.014)

Bosch J, Yusuf S, Gerstein HC, Pogue J, Sheridan P, Dagenais G, Diaz R, Avezum A, Lanas F, Probstfield J, et al. 2006 Effect of ramipril on the incidence of diabetes. New England Journal of Medicine $\mathbf{3 5 5}$ 1551-1562. (doi:10.1056/NEJMoa065061)

Browning JD \& Horton JD 2004 Molecular mediators of hepatic steatosis and liver injury. Journal of Clinical Investigation 114 147-152. (doi:10.1172/JCI200422422)

Carlsson PO, Berne C \& Jansson L 1998 Angiotensin II and endocrine pancreas: effects on islets blood flow and insulin secretion in rats. Diabetologia 41 127-133. (doi:10.1007/s001250050880)

Carrie E McCurdy CE, Davidson RT \& Cartee GD 2003 Brief calorie restriction increases Akt 2 phosphorylation in insulin stimulated rat skeletal muscle. American Journal of Physiology: Endocrinology and Metabolism 285 E693-E700. (doi:10.1152/ ajpendo.00224.2003)
Cassis LA, Dana EM, Fettinger MJ, Brady R \& Robert AL 1998 Mechanism contributing to angiotensin II regulation of body weight. American Journal of Physiology: Endocrinology and Metabolism 274 E867-E876.

Catt KJ, Cain MD, Zimmet PZ \& Cran E 1969 Blood angiotensin II levels of normal and hypertensive subjects. BMJ 1 819-821. (doi:10.1136/ bmj.1.5647.819)

Cortez MY, Torgan CE, Brozinick JT Jr \& Ivy JL 1991 Insulin resistance of obese Zucker rats exercise trained at two different intensities. American Journal of Physiology 261 E613-E619.

de Kloet AD, Krause EG \& Woods SC 2010 The renin angiotensin system and the metabolic syndrome. Physiology and Behavior 100 525-534. (doi:10.1016/j.physbeh.2010.03.018)

DeFronzo RA \& Tripathy D 2009 Skeletal muscle insulin resistance is the primary defect in type 2 diabetes. Diabetes Care 32 (Supplement 2) S157-S163. (doi:10.2337/dc09-S302)

Deji N, Kume S, Araki S, Isshiki K, Araki H, Chin-Kanasaki M, Tanaka Y, Nishiyama A, Koya D, Haneda M, et al. 2012 Role of angiotensin II-mediated AMPK inactivation on obesity-related salt-sensitive hypertension. Biochemical and Biophysical Research Communications 418 559-564. (doi:10.1016/j.bbrc.2012.01.070)

Echeverria-Rodriguez O, Del Valle-Mondragon L \& Hong E 2014 Angiotensin 1-7 improves insulin sensitivity by increasing skeletal muscle glucose uptake in vivo. Peptides 51 26-30. (doi:10.1016/j. peptides.2013.10.022)

Fernandes T, Hashimoto NY \& Oliveira EM 2010 Characterization of angiotensin-converting enzymes 1 and 2 in the soleus and plantaris muscles of rats. Brazilian Journal of Medical and Biological Research 43 837-842. (doi:10.1590/S0100879X2010007500088)

Ferrario CM, Trask AJ \& Jessup JA 2005 Advances in biochemical and functional roles of angiotensin-converting enzyme 2 and angiotensin-(1-7) in regulation of cardiovascular function. American Journal of Physiology: Heart and Circulatory Physiology 289 H2281-H2290. (doi:10.1152/ajpheart. 00618.2005)

Giani JF, Mayer MA, Munoz MC, Silberman EA, Hocht C, Taira CA, Gironacci MM, Turyn D \& Dominici FP 2009 Chronic infusion of angiotensin-(1-7) improves insulin resistance and hypertension induced by a high-fructose diet in rats. American Journal of Physiology: Endocrinology and Metabolism 296 E262-E271. (doi:10.1152/ ajpendo.90678.2008)

Gress TW, Nieto FJ, Shahar E, Wofford MR \& Brancati FL 2000 Hypertension and antihypertensive therapy as risk factors for type 2 diabetes mellitus. Atherosclerosis Risk in Communities Study. New England Journal of Medicine 342 905-912. (doi:10.1056/ NEJM200003303421301)

Hardie DG 2003 Minireview: the AMP-activated protein kinase cascade: the key sensor of cellular energy status. Endocrinology 144 5179-5183. (doi:10.1210/en.2003-0982)

Henriksen EJ \& Halseth AE 1994 Early alterations in soleus GLUT-4, glucose transport, and glycogen in voluntary running rats. Journal of Applied Physiology 76 1862-1867.

Henriksen EJ, Jacob S, Kinnick TR, Teachey MK \& Krekler M 2001 Selective angiotensin II receptor antagonism reduces insulin resistance in obese Zucker rats. Hypertension 38 884-890. (doi:10.1161/hy1101.092970)

Henriksen EJ, Diamond-Stanic MK \& Marchionne EM 2011 Oxidative stress and the etiology of insulin resistance and type 2 diabetes. Free Radical Biology and Medicine 51 993-999. (doi:10.1016/j. freeradbiomed.2010.12.005)

Huang BS, Ahmadi S, Ahmad M, White RA \& Leenen FH 2010 Central neuronal activation and pressor responses induced by circulating ANG II: role of the brain aldosterone-'ouabain' pathway. American Journal of Physiology: Heart and Circulatory Physiology 299 H422-H430. (doi:10.1152/ajpcell.00562.2009) 
Jacob S, Henriksen EJ, Fogt DL \& Dietze GJ 1996 Effects of Trandolapril and Verapamil on glucose transport in insulin-resistant rat skeletal muscle. Metabolism 45 535-541. (doi:10.1016/S0026-0495(96)90021-9)

Kim JS, Saengsirisuwan V, Sloniger JA, Teachey MK \& Henriksen EJ 2006 Oxidant stress and skeletal muscle glucose transport: roles of insulin signaling and p38 MAPK. Free Radical Biology and Medicine 41 818-824. (doi:10.1016/j.freeradbiomed.2006.05.031)

Lastra G, Santos FR, Hooshmand P, Hooshmand P, Mugerfeld I, Aroor AR, Demarco VG, Sowers JR \& Henriksen EJ 2013 The novel angiotensin II receptor blocker azilsartan medoxomil ameliorates insulin resistance induced by chronic angiotensin II treatment in rat skeletal muscle. CardioRenal Medicine 3 154-164. (doi:10.1159/000353155)

Luther JM \& Brown NJ 2011 The renin-angiotensin-aldosterone system and glucose homeostasis. Trends in Pharmacological Sciences 32 734-739. (doi:10.1016/j.tips.2011.07.006)

McCurdy CE \& Cartee GD 2005 Akt2 is essential for the full effect of calorie restriction on insulin-stimulated glucose uptake in skeletal muscle. Diabetes 54 1349-1356. (doi:10.2337/diabetes.54.5.1349)

Müller H, Schweitzer N, Johren O, Dominiak P \& Raasch W 2007 Angiotensin II stimulates the reactivity of the pituitary-adrenal axis in leptin-resistant Zucker rats, thereby influencing the glucose utilization. American Journal of Physiology: Endocrinology and Metabolism 293 E802-E810. (doi:10.1152/ajpendo. 00650.2006)

Nicola W, Sidhom G, Khyat ZE, Ibrahim S, Salah A \& Sayed AE 2001 Plasma angiotensin II, renin activity and serum angiotensinconverting enzyme activity in non-insulin dependent diabetes mellitus patients with diabetic nephropathy. Endocrine Journal 48 25-31. (doi:10.1507/endocrj.48.25)

Ogihara T, Asano T, Ando K, Chiba Y, Sakoda H, Anai M, Shojima N, Ono H, Onishi Y, Fujishiro M, et al. 2002 Angiotensin II-induced insulin resistance is associated with enhanced insulin signaling. Hypertension 40 872-879. (doi:10.1161/01.HYP.0000040262. 48405.A8)

Osborn JW, Fink GD \& Kuroki MT 2011 Neural mechanisms of angiotensin II-salt hypertension: implications for therapies targeting neural control of the splanchnic circulation. Current Hypertension Reports 13 221-228. (doi:10.1007/s11906-011-0188-9)

Park SY, Choi GH, Choi HI, Ryu J, Jung CY \& Lee W 2005 Calorie restriction improves whole-body glucose disposal and insulin resistance in association with the increased adipocyte-specific GLUT4 expression in Otsuka Long-Evans Tokushima fatty rats. Archives of Biochemistry and Biophysics 436 276-284. (doi:10.1016/ j.abb.2005.01.010)

Prasannarong M, Santos FR \& Henriksen EJ 2012a ANG-(1-7) reduces ANG II-induced insulin resistance by enhancing Akt phosphorylation via a Mas receptor-dependent mechanism in rat skeletal muscle. Biochemical and Biophysical Research Communications 426 369-373. (doi:10.1016/j.bbrc.2012.08.093)

Prasannarong M, Vichaiwong K \& Saengsirisuwan V 2012b Calorie restriction prevents the development of insulin resistance and impaired insulin signaling in skeletal muscle of ovariectomized rats. Biochimica et Biophysica Acta 1822 1051-1061. (doi:10.1016/ j.bbadis.2012.02.018)

Qin Z 2008 Newly developed angiotensin II-infused experimental models in vascular biology. Regulatory Peptides 150 1-6. (doi:10.1016/ j.regpep.2008.05.002)

Ran J, Hirano T \& Adachi M 2004 Chronic ANG II infusion increases plasma triglyceride level by stimulating hepatic triglyceride production in rats. American Journal of Physiology: Endocrinology and Metabolism 287 E955-E961. (doi:10.1152/ajpendo.00199.2004)

Ran J, Hirano T \& Adachi M 2005 Angiotensin II infusion increases hepatic triglyceride production via its type 2 receptor in rats. Journal of Hypertension 23 1525-1530. (doi:10.1097/01. hip.0000174077.88121.19)
Reaven GM 2005 The insulin resistance syndrome: definition and dietary approaches to treatment. Annual Review of Nutrition 25 391-406. (doi:10.1146/annurev.nutr.24.012003.132155)

Ruderman NB, Carling D, Prentki M \& Cacicedo JM 2013 AMPK, insulin resistance, and the metabolic syndrome. Journal of Clinical Investigation 123 2764-2772. (doi:10.1172/JCI67227)

Santos SH \& Andrade JM 2014 Angiotensin 1-7: a peptide for preventing and treating metabolic syndrome. Peptides 59 34-41. (doi:10.1016/j. peptides.2014.07.002)

Santos RA, Ferreira AJ, Simoes E \& Silva AC 2008 Recent advances in the angiotensin-converting enzyme 2-angiotensin(1-7)Mas axis. Experimental Physiology 93 519-527. (doi:10.1113/ expphysiol.2008.042002)

Santos FR, Diamond-Stanic MK, Prasannarong M \& Henriksen EJ 2012 Contribution of the serine kinase c-Jun N-terminal kinase (JNK) to oxidant-induced insulin resistance in isolated rat skeletal muscle. Archives of Physiology and Biochemistry 118 231-236. (doi:10.3109/138 13455.2012.713366)

Santos RA, Ferreira AJ, Verano-Braga T \& Bader M 2013 Angiotensinconverting enzyme 2 , angiotensin-(1-7) and Mas: new players of the renin-angiotensin system. Journal of Endocrinology 216 R1-R17. (doi:10.1530/JOE-12-0341)

Sloniger JA, Saengsirisuwan V, Diehl CJ, Dokken BB, Lailerd N, Lemieux AM, Kim JS \& Henriksen EJ 2005 Defective insulin signaling in skeletal muscle of the hypertensive TG(mREN2)27 rat. American Journal of Physiology: Endocrinology and Metabolism 288 E1074-E1081. (doi:10.1152/ajpcell.00391.2004)

Song B, Jin H, Yu X, Zhang Z, Yu H, Ye J, Xu Y, Zhou T, Oudit GY, Ye JY, et al. 2013 Angiotensin-converting enzyme 2 attenuates oxidative stress and VSMC proliferation via the JAK2/STAT3/SOCS3 and profilin-1/MAPK signaling pathways. Regulatory Peptides $\mathbf{1 8 5}$ 44-51. (doi:10.1016/j.regpep.2013.06.007)

Sower JR 2004 Insulin resistance and hypertension. American Journal of Physiology: Heart and Circulatory Physiology 286 H1597-H1602. (doi:10.1152/ajpheart.00026.2004)

Speakman JR \& Mitchell SE 2011 Caloric restriction. Molecular Aspects of Medicine 32 159-221. (doi:10.1016/j.mam.2011.07.001)

Staroukine M, Devriendt J, Decoodt P \& Verniory A 1984 Relationships between plasma epinephrine, norepinephrine, dopamine and angiotensin II concentrations, renin activity, hemodynamic state and prognosis in acute heart failure. Acta Cardiologica 32 131-138.

Takeda M, Yamamoto K, Takemura Y, Takeshita H, Hongyo K, Kawai T, Hanasaki-Yamamoto H, Oguro R, Takami Y, Tatara Y, et al. 2013 Loss of ACE2 exaggerates high-calorie diet-induced insulin resistance by reduction of GLUT4 in mice. Diabetes 62 223-233. (doi:10.2337/ db12-0177)

Towler MC \& Hardie DG 2007 AMP-activated protein kinase in metabolic control and insulin signaling. Circulation Research 100 328-341. (doi:10.1161/01.RES.0000256090.42690.05)

Vichaiwong K, Henriksen EJ, Toskulkao C, Prasannarong M, Bupha-Intr T \& Saengsirisuwan V 2009 Attenuation of oxidantinduced muscle insulin resistance and p38 MAPK by exercise training. Free Radical Biology and Medicine 47 593-599. (doi:10.1016/j. freeradbiomed.2009.05.036)

Wang P, Zhang RY, Song J, Guan YF, Xu TY, Du H, Viollet B \& Miao CY 2012 Loss of AMPK alpha2 impaires the insulin-sensitizing effect of calorie restriction in skeletal muscle. Diabetes 61 1051-1061. (doi:10.2337/db11-1180)

Wang H, Arias EB \& Cartee GD 2016 Calorie restriction leads to greater Akt2 activity and glucose uptake by insulin-stimulated skeletal muscle from old rats. American Journal of Physiology: Regulatory, Integrative and Comparative Physiology 310 R449-R458. (doi:10.1152/ ajpcell.00092.2016)

Wei Y, Sowers JR, Nistala R, Gong H, Uptergrove GM, Clark SE, Morris EM, Szary N, Manrique C \& Stump CS 2006 Angiotensin

Published by Bioscientifica Ltd. 
II-induced NADPH oxidase activation impairs insulin signaling in skeletal muscle cells. Journal of Biological Chemistry 281 35137-35146. (doi:10.1074/jbc.M601320200)

Wei Y, Sowers JR, Clark SE, Li W, Ferrario CM \& Stump CS 2008 Angiotensin II-induced skeletal muscle insulin resistance mediated by NF-kappaB activation via NADPH oxidase. American Journal of Physiology: Endocrinology and Metabolism 294 E345-E351. (doi:10.1152/ajpcell.00216.2007)

Yoshida D, Higashiura K, Shinshi Y, Satoh K, Hyakkoku M, Yoshida H, Miyazaki Y, Ura N \& Shimamoto K 2009 Effects of angiotensin II receptor blockade on glucose metabolism via AMP-activated protein kinase in insulin-resistant hypertensive rats. Journal of the American Society of Hypertension 3 3-8. (doi:10.1016/j.jash.2008.08.002)

Zhou MS, Liu C, Tian R, Nishiyama A \& Raij L 2015 Skeletal muscle insulin resistance in salt-sensitive hypertension: role of angiotensin II activation of NFkappaB. Cardiovascular Diabetology 1445. (doi:10.1186/s12933-015-0211-6)

Zimmerman MA, Harris RA \& Sullivan JC 2014 Female spontaneously hypertensive rats are more dependent on ANG (1-7) to mediate effects of low-dose AT1 receptor blockade than males. American Journal of Physiology: Renal Physiology 306 F1136-F1142. (doi:10.1152/ ajprenal.00677.2013)

Received in final form 13 January 2017

Accepted 17 January 2017

Accepted Preprint published online 17 January 2017
Published by Bioscientifica Ltd. 